\title{
Preparation of Wheat Germ Oil Loaded Solid Lipid Nanoparticles for Topical use
}

\author{
Nesrein M. Bendala ${ }^{1,2}$, Abdurrauf M. Gusbi², Nagib A. Elmarzugi ${ }^{1,2}$
}

${ }^{1}$ National Nanosciences \& Nanotechnology Project, Biotechnology Research Centre, Tripoli, Libya

2 Faculty of Pharmacy, The University of Tripoli, Tripoli, Libya

*Email: n.elmarzugi@uot.edu.ly

\section{- INTRODUCTION}

The cosmetic industry has recently begun to take advantage of the special properties of nanoparticles. One of the nanotechnology product that has attracted significant interest among researchers is Solid Lipid Nanoparticles (SLN), and that is due to their physical stability, protection of incorporated labile drugs from degradation, controlled release and excellent tolerability ${ }^{1,2}$. In general, lipid nanoparticles have several advantages as topical administration system, which are, high compatibility with the skin as lipids are in the normal components of its structure, low cost, easy to scale up to industrial scale ${ }^{3,4}$, enhance penetration of active compounds in the stratum corneum, good physical stability and controlled release profiles ${ }^{4,5}$.

Recently, the increasing demand for pharmaceutical and cosmetic products containing natural active ingredients has brought researchers to focus more on essential oils (EO) ${ }^{6}$. The wheat germ oil is known to be the richest source of vitamin $E, A$ and $D$ due to this it helps in getting rid of skin irritation including skin dryness and cracking. When applied to the skin, it improves the circulation of blood and helps in repairing skin cells affected by the heat of the sun ${ }^{7}$.

\section{- METHODS AND MATERIAL}

Wheat germ was obtained directly after milling from The Joint Stock National Company for Flour Mills and Fodder - South Tripoli Mill. The wheat germ was then ground and soaked in hexane for 10 days for the oil extraction.

1- Hot Homogenization Method

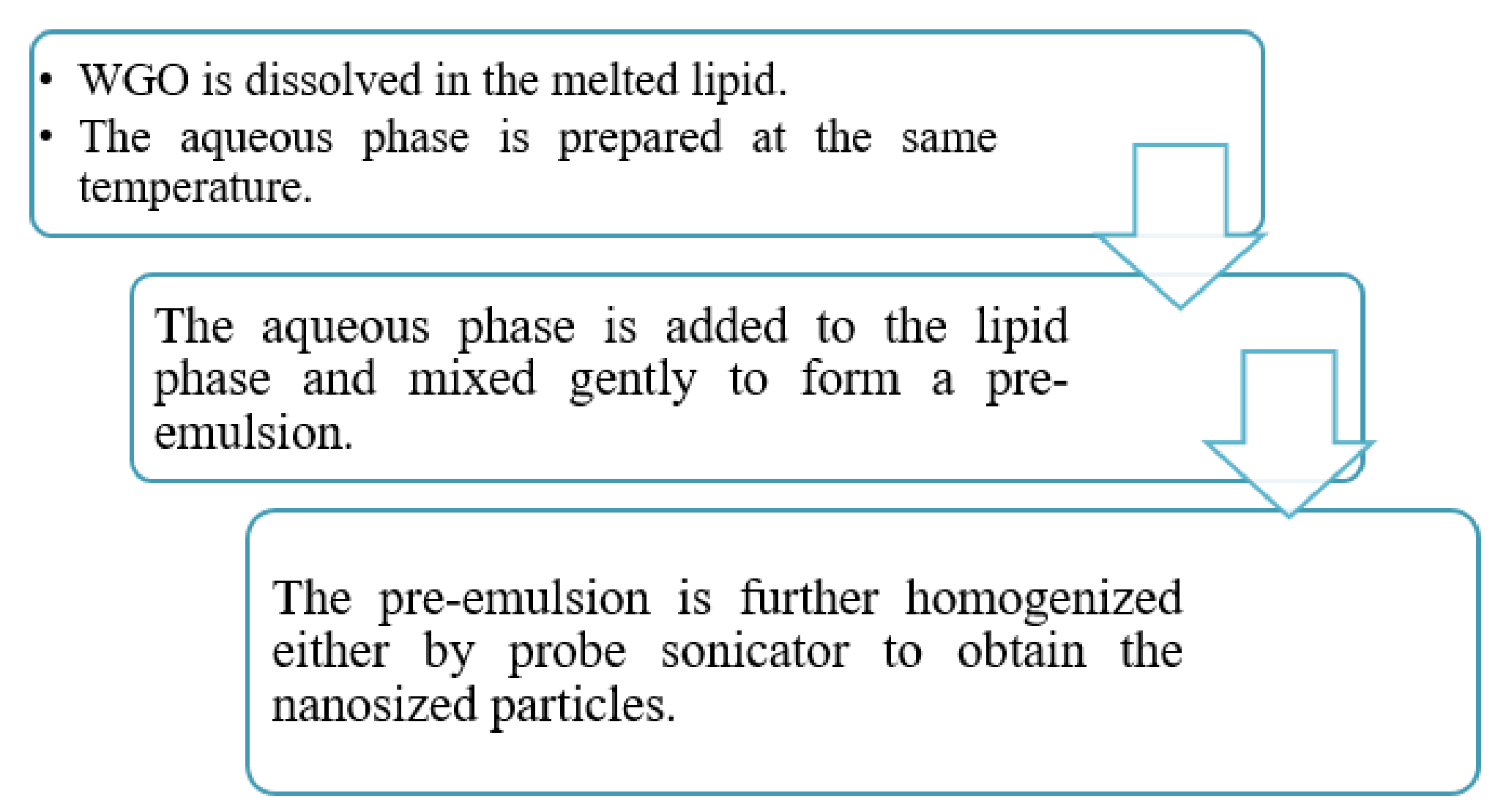

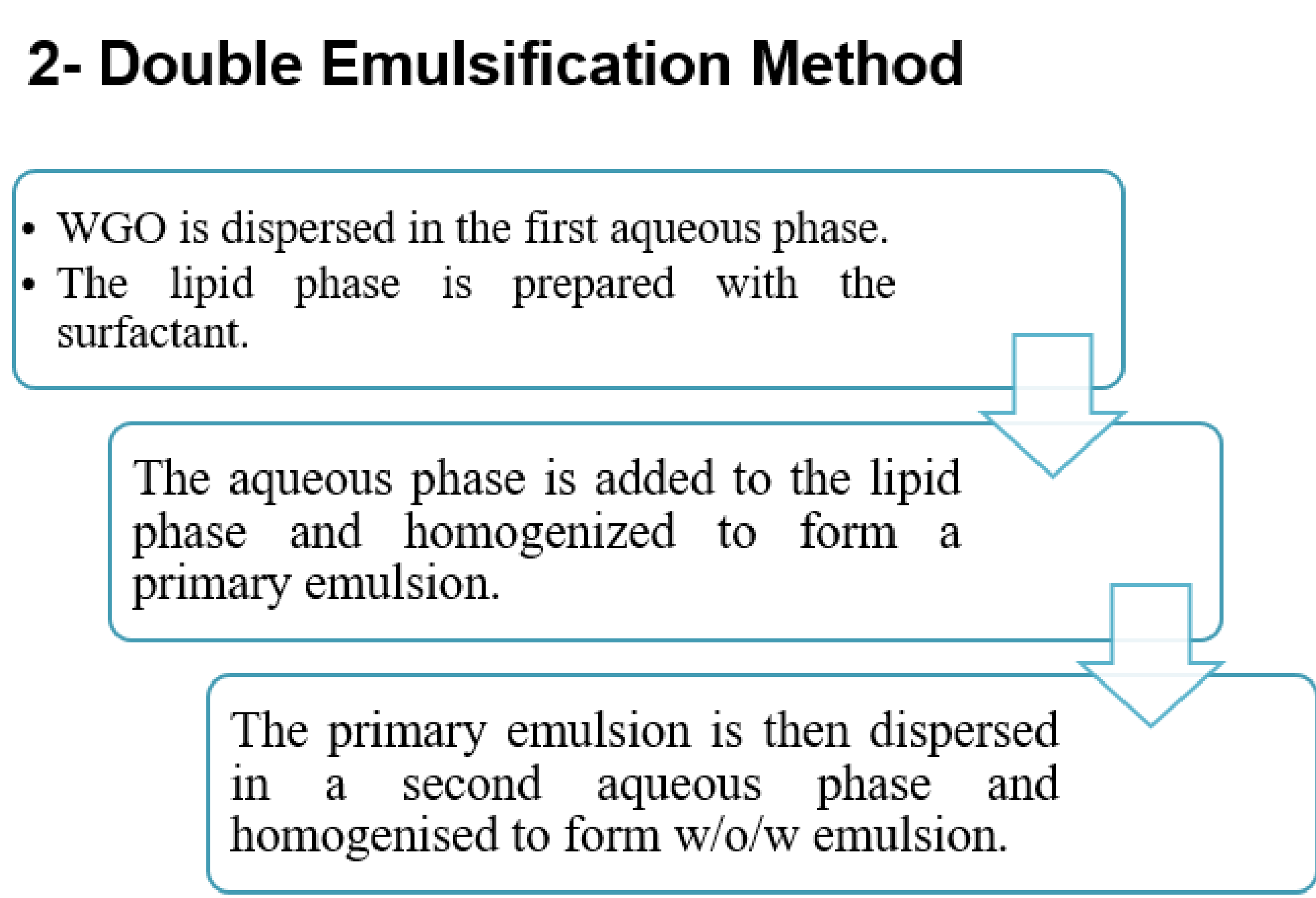

\section{- $\quad$ RESULTS AND DISCUSSION}

According to particle size and PDI, it is notices that, in both methods, the samples with lower concentration of lipid and surfactant presents smaller particle sizes and more narrow PDI value than the samples with higher concentrations. This result alone gives us the impression that the lower concentration samples present better products than the samples with higher concentrations. However, by looking at the images obtained from TEM it is clear that the samples with the lower concentrations are less stable, as they both did not show any clear structure of nanoparticles. On the other hand, the samples with higher concentrations, in both methods, showed clear spherical particles surrounded with surfactants and in the nanosize range. This could be contributed to the presence of higher amount of surfactants in these samples.

\section{- CONCLUSION}

WGO-SLNs were successfully produced by the double emulsification method and the hot homogenisation method. According to particle size all the products were in the nanometre range and generally homogenous. On the other hand, when examining the surface morphology of the products it was clear that the products with the higher concentration of lipid and surfactant gave more stable particle with clear spherical shape. Nonetheless, hot homogenisation method is economic, simple, reproducible and most preferred method for the preparation of SLNs. Its main advantage over double emulsification method is that it does not require any organic solvents, which are difficult to remove from the preparation.
- Particle size and Polydispersity Index of WGO loaded SLNs.

\begin{tabular}{|l|l|l|}
\hline Sample & $\begin{array}{l}\text { Particle size }(\mathbf{n m}) \\
\text { Average } \pm \text { SD }\end{array}$ & PDI $^{*}$ \\
\hline M1F1 & $240 \pm 124.7$ & 0.192 \\
\hline M1F4 & $364.3 \pm 237.2$ & 0.210 \\
\hline M2F1 & $194.4 \pm 40.3$ & 0.171 \\
\hline M2F4 & $288.5 \pm 154.4$ & 0.240 \\
\hline *PDI: Polydispersity Index & & \\
\hline
\end{tabular}

References:

1.

do 1

$2.10 .1016 /$ j.nano.2008.06.002

Souto EB, Muller RH. Cosmetic features and applications of lipid nanoparticles (SLN ${ }^{\circledR}$, NLC ${ }^{\circledR}$ ). Int J Cosmet Sci. 2008;30:157-165.

3. Sarathchandiran I. A Review On Nanotechnology In Solid Lipid Nanoparticles. Int J Pharm Dev Technol. 2012;2(1):45-61.

doi:10.1111/ics.12452

Saez V, Souza IDL, Mansur CRE. Lipid nanoparticles (SLN \& NLC) for delivery of vitamin E: a comprehensive review. Int J Cosmet Sci. 2018;40(2):103-116.

5. Patel D, Kumar V, Kesharwani R, Mazumdar B. Lipid nanoparticle a novel carrier for cosmetics and topical preparation: a review. Inven Rapid Cosmeceuticals. 2015;2015(3):1-6.

6. Pharmaceutics. 2017;9(4):1-12. doi:10.3390/pharmaceutics9040048

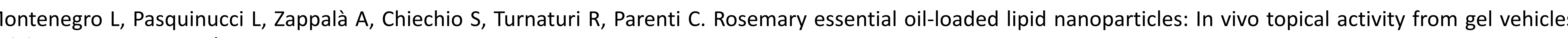

Kumar P, Yadava R, Gollen B, Kumar S, Verma R, Yadav S. Nutritional Contents and Medicinal Properties of Wheat : A Review. Life Sci Med Res. 2011;2011(22):1-10. 